\title{
Epidemiological modelling of the health and economic effects of COVID-19 control in Australia's second wave
}

\author{
R. Quentin Grafton ${ }^{1}$ (D) John Parslow ${ }^{2} \cdot$ Tom Kompas $^{3}$ (D) Kathryn Glass $^{4}$ (D) Emily Banks $^{4}$ (D)
}

Received: 2 January 2021 / Accepted: 8 June 2021

(C) The Author(s) 2021

\begin{abstract}
Background We investigated the public health and economy outcomes of different levels of social distancing to control a 'second wave' outbreak in Australia and identify implications for public health management of COVID-19.

Methods Individual-based and compartment models were used to simulate the effects of different social distancing and detection strategies on Australian COVID-19 infections and the economy from March to July 2020. These models were used to evaluate the effects of different social distancing levels and the early relaxation of suppression measures, in terms of public health and economy outcomes.

Results The models, fitted to observations up to July 2020, yielded projections consistent with subsequent cases and showed that better public health outcomes and lower economy costs occur when social distancing measures are more stringent, implemented earlier and implemented for a sufficiently long duration. Early relaxation of suppression results in worse public health outcomes and higher economy costs.

Conclusions Better public health outcomes (reduced COVID-19 fatalities) are positively associated with lower economy costs and higher levels of social distancing; achieving zero community transmission lowers both public health and economy costs compared to allowing community transmission to continue; and early relaxation of social distancing increases both public health and economy costs.
\end{abstract}

Keywords Pandemic $\cdot$ SARS-CoV-2 $\cdot$ Individual based models $\cdot$ Compartment models $\cdot$ Social distancing

\section{Introduction}

Australia recorded its first case of COVID-19 on 25 January 2020 from a person who had flown from China on 19 January (Hunt 2020). Initial national daily cases peaked at 458 on 28 March 2020 and, thereafter, declined due to border measures for overseas arrivals, self-quarantine, wide-spread testing and contact tracing, and social distancing outside of households

Tom Kompas

tom.kompas@unimelb.edu.au

1 Crawford School of Public Policy, The Australian National University, Canberra, Australian Capital Territory, Australia

2 Hobart, Australia

3 Centre of Excellence for Biosecurity Risk Analysis, School of Biosciences, University of Melbourne, Melbourne, Victoria 3010, Australia

4 College of Health and Medicine, The Australian National University, Canberra, Australian Capital Territory, Australia that changed the frequency, the numbers and the nature of physical contacts (Australian Department of Health 2020a). By 9 June 2020, there were only two new recorded cases in Australia.

At the end of May, in the Australian state of Victoria, a 'second wave' of COVID-19 began following an outbreak from hotel quarantine. Additional public health measures were reinstituted in the second half of June in Victoria, including a 'stage 3' lockdown in the state capital, Melbourne, and the nearby Mitchell Shire, on 9 July for a 6-week period. These measures slowed the growth in infections (Saul et al. 2020) but failed to stop an increase in COVID-19 infections. On 5 August 2020, when new daily cases peaked at 687 in Victoria, there were approximately 20,000 reported cumulative cases in Australia, of which some 11,000 had recovered; with 250 COVID-19 fatalities (162 in Victoria) (Australian Department of Health 2020b).

A highly stringent lockdown, with mandated social distancing measures, began in Victoria in early August 2020. These measures were gradually relaxed from mid-September 
as infections were effectively suppressed (Blakely et al. 2020) followed a 'Roadmap for Reopening' pre-determined by the 14-day average of new daily cases (Victorian Department of Health and Social Services 2020). Major relaxation of social distancing measures occurred on 27 October (step 3) and 22 November (last step) (Grafton et al. 2020). On 6 December 2020, Victoria returned to 'COVID-normal' because no new cases had been diagnosed since 31 October.

Key public health and economy questions facing Australia, and the world, in relation to supressing COVID-19 infections are: What levels of social distancing are required to adequately reduce infections associated with a 'second wave' of COVID19 infections? What is the probability of achieving elimination (defined as no community transmission (Group of 8 Universities 2020)) with various levels of lockdown and duration? What are the public health and economy costs of different stringency levels of social distancing?

Our contribution is to show: (1) Epidemiological modelling, undertaken at the peak of the second wave, can provide a reasonable approximation of the actual suppression outcomes (cases) associated with highly stringent social distancing; (2) A combination of epidemiological models, coupled with economy cost measures, show that public health outcomes are associated with lower economy costs; (3) Different epidemiological (individual based, deterministic compartment and stochastic compartment) models can be complementary and provide comparable simulated results; (4) the importance of a sufficiently long enough duration of social distancing, if elimination of community transmission is the goal; and (5) the public health dangers of outbreaks from quarantine even with very low levels of occurrence.

\section{Materials and methods}

\section{Model description}

The simulation model used here is one of a suite of epidemiological models developed to support the study and management of the COVID-19 outbreak in Australia. The suite builds on a stochastic individual-based or agent-based model (IBM), which follows infected individuals through multiple stages and alternative fates as the disease progresses. Individualbased models are flexible but are computationally expensive to run when the number of individuals becomes large. This makes IBM more difficult to undertake rigorous statistical calibration, or to run large ensembles to quantify stochastic variation. Thus, we developed a more computationally efficient analogue of the IBM: a stochastic compartment model (SCM) which followed daily cohorts of infected individuals through the same stages and fates. For extremely demanding computations, including Monte Carlo-based Bayesian inference, the SCM was approximated by a simpler deterministic compartment model (DCM) that follows daily cohorts through the same stages and fates, except that probabilistic transitions are replaced by proportional allocations.

The model suite represents the public health measures implemented in Australia in an attempt to prevent or limit outbreaks. These measures include: testing; contact tracing; selfquarantine/self-isolation of detected cases and contacts; border controls (self-quarantine and then hotel quarantine of overseas arrivals); and social distancing directives. Our model suite predicts the number of new infected cases each day as a result of transmission from current infectious cases, taking into account the effects of self-isolation and self-quarantine.

This section provides an overview of the model structure and function. Further details are provided in Appendix 1.

\section{Disease progression}

The model suite represents the key stages and possible outcomes in the evolution of COVID-19 infection, as portrayed in Fig. 1. Some asymptomatic COVID-19 cases never develop symptoms, but do become infectious, although they are believed to be less infectious than symptomatic cases. Newly infected cases in the model are immediately assigned to either an asymptomatic category (with probability $\mathrm{P}_{\mathrm{A}}$ ) or a symptomatic category with probability $\left(1-\mathrm{P}_{\mathrm{A}}\right)$. Those in the symptomatic category do not develop symptoms until $\mathrm{T}_{\mathrm{S}}$ days postinfection. The timing of the onset of symptoms matters because, at least during the period considered in this study, testing (and therefore detection, reporting and contact tracing) in Australia were mostly confined to those displaying symptoms.

Both asymptomatic and symptomatic categories become infectious after $T_{I}$ days. Importantly, transmission can occur at least 1 to 2 days before symptoms became apparent $\left(T_{I}<\right.$ $\mathrm{T}_{\mathrm{S}}$ ), hindering attempts to control COVID-19 outbreaks. In our model suite, the infectious period ends at $\mathrm{T}_{\mathrm{F}}$ days, chosen so as to yield appropriate values for the reproductive number $\mathrm{R} 0$ and the growth rate of uncontrolled outbreaks.

A proportion of COVID-19 patients develop severe symptoms requiring hospital admission. In our model suite, this occurs after $\mathrm{T}_{\mathrm{H}}$ days, with probability $\mathrm{P}_{\mathrm{H}}$. Of those admitted to hospital, a further proportion will develop fatal complications, with probability $\mathrm{P}_{\mathrm{M}}$. Those with fatal complications die with daily probability $\mathrm{P}_{\mathrm{D}}$, starting $\mathrm{T}_{\mathrm{D}}$ days after infection. All other patients start to recover with daily probability $\mathrm{P}_{\mathrm{R}}$, begin$\operatorname{ning} T_{R}$ days after infection. Our model suite only tracks cases for a maximum period of $\mathrm{T}_{\mathrm{M}}$ days after infection after which cases have either recovered or died. Transitions in status related to onset of symptoms, onset and cessation of infectivity, and hospital admission occur simultaneously across all individuals in the same cohort. We developed versions of the models which allow these transitions to be spread over windows of multiple days noting that this made a negligible difference to our simulations. 
Fig. 1 Model suite representation of COVID-19 progression

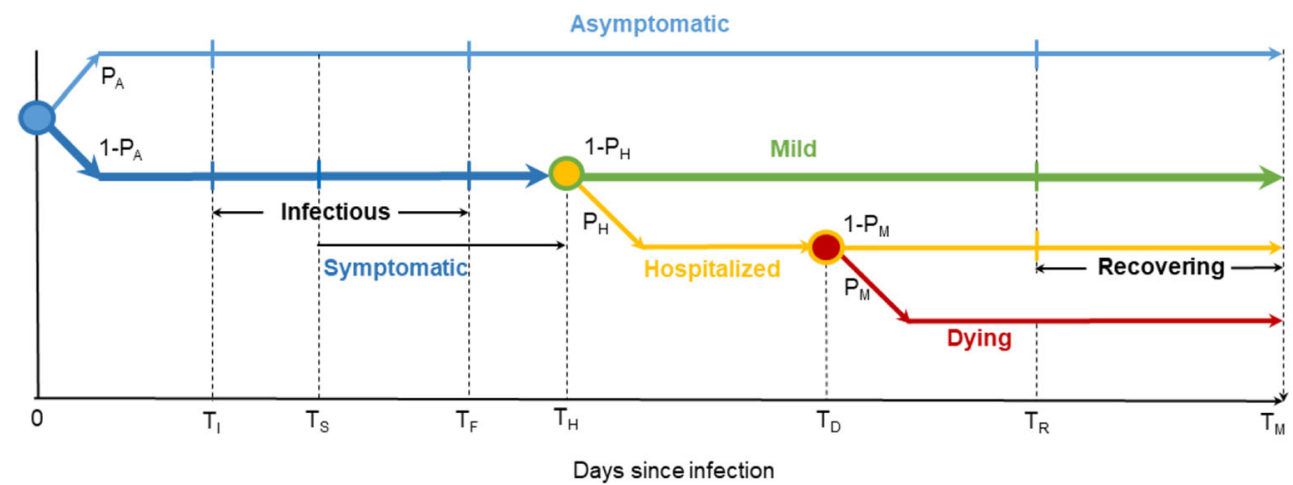

\section{Control measures}

Testing and detection of symptomatic cases occur in the model suite either through community testing, or through testing of those in self-quarantine or self-isolation. Community testing of cases self-reporting with symptoms was less effective in the first wave in Australia (March to May), as tests were in short supply and only contacts of overseas arrivals or known cases were tested. In Victoria's second wave, attendance at community testing clinics was strongly encouraged, although some studies suggest only a modest proportion of those with COVID-19-like symptoms volunteered to be tested. In the model suite, the daily probability for a symptomatic case being tested and detected as positive at a community testing centre were allowed to increase from a low value of 0.2 in the first wave, to a higher value $\mathrm{P}_{\mathrm{DC}}$ after June.

Testing and detection of symptomatic cases already in selfquarantine is assumed to be more effective, and their daily probability of detection $\mathrm{P}_{\mathrm{DSQ}}$ is set to 0.8 . The model assumes that all severe cases are tested and detected on admission to hospital.

Contact tracing has been a key and controversial public health measure against COVID-19 in Australia, and its representation in the model has been given particular attention. For each new infected case, the IBM keeps track of the ID of the responsible source case. If and when its source case is detected, an (undetected) case becomes eligible to be traced, with a daily probability $\mathrm{P}_{\mathrm{T}}$. Once traced, cases are placed in self-quarantine noting that all detected cases are required to self-isolate.

The representation of contact tracing in the SCM and DCM is more challenging. In these models, only the numbers of cases in subcategories within a daily cohort are known. Our model suite tracks the proportions of detected cases within source cohorts, weighted by their relative contributions to each new cohort. They use this to calculate the proportion of members in each daily cohort which become subject to contact tracing. This calculation cannot replicate exactly the tracking of individual sources in the IBM, but provides a good approximation, allowing the SCM to closely replicate ensemble output from the IBM.
A highly effective contact tracing program would be expected to have values of the $24 \mathrm{~h}$ tracing efficiency $\mathrm{P}_{\mathrm{T}}$ close to 1. Simulations show that contact tracing can still be highly effective with much lower values of $\mathrm{P}_{\mathrm{T}}$ because the proportion of detected cases builds cumulatively over time. In the Victorian second wave, contact tracing by itself was insufficient to stop growth in infections and a severe lockdown was eventually imposed. We reproduced this fact in the model suite by assuming that a proportion $\mathrm{P}_{\mathrm{U}}$ of infected cases were permanently undetected and untraceable.

Contact tracing is resource intensive, especially as the number of cases increases. For each detected case, a number of downstream contacts of order 10 must be identified, contacted, asked to self-quarantine, and monitored for development of symptoms, and to check compliance, for 14 days. Thus, for 100 daily detected cases, contact tracers could have up to 14,000 contacts under management. The Australia-wide tracing capacity $\mathrm{T}_{\mathrm{CAP}}$ is assumed to be between 100 and 500 daily detected cases but we note that in specific jurisdictions, such as Victoria during its second wave, the capacity could have been below 100 new daily cases, in the absence of endto-end automated process for enabling and recording contact tracing (Legal and Social Issues Committee 2020).

Australian border controls are implemented in the model as quarantine requirements on overseas arrivals. After 17 March 2020, overseas arrivals were required to self-quarantine at home. After 28 March they were required to enter hotel quarantine. The model simulations provided here are driven by reported numbers of daily detected COVID-19 cases among overseas arrivals in Australia. Positive overseas arrivals in quarantine are assumed to be detected immediately upon displaying symptoms and are represented in the model as new infectives appearing $T_{S}$ days before being reported. Reported overseas cases are assumed to be accompanied by additional undetected asymptomatic cases, in the ratio $\mathrm{P}_{\mathrm{A}}: 1-\mathrm{P}_{\mathrm{A}}$.

Social distancing (SD) or lockdown measures have played a key role in controlling both the first and second waves in Australia. The model suite represents SD implicitly as changes in the effective daily transmission rate $\mathrm{G}$ (new infections per infectious case per day). The maximum transmission rate in 
the absence of social distancing is denoted by G0. The minimum transmission rate achieved during the severe nationwide lockdown in April 2020, which ended the first wave, is denoted by $\mathrm{G}_{\mathrm{LD}}$. Movement data suggest there was a gradual relaxation following the first wave, up until early July. The extent of this relaxation of SD in early July is measured by the parameter RSD given by (G-GLD)/(G0-GLD). In the control scenarios described later, social distancing stringency is characterised by the control variable $\mathrm{SD}=(\mathrm{G} 0-\mathrm{G}) /(\mathrm{G} 0-$ GLD).

\section{Transmission}

In the IBM, the number of daily new infections produced by an infected individual is assumed to be a random variable drawn from an over-dispersed negative binomial distribution with mean $\mathrm{G}$ and dispersion coefficient k'. In the SCM, the number of daily new infections from a pool of $\mathrm{X}$ infectious individuals is then also negative binomial, with adjusted parameters G. X and k'.X. The choice of the dispersion parameter k' is discussed further in the Appendix. In the DCM, the number of new daily infections is just the expected value G.X.

Individuals have different transmission rates, depending on their status. Cases in the asymptomatic category are assumed to have a mean transmission rate equal to $\mathrm{F}_{\mathrm{A}}$ times that of those in the symptomatic category. While there should be zero transmission from cases in self-isolation or self-quarantine, in practice some transmission occurs. The model suite assumes the transmission rate from those in self-quarantine or selfisolation is reduced by the 'leakage' factor $\mathrm{P}_{\mathrm{L}}$.

Hotel quarantine was initially assumed to be $100 \%$ effective in preventing transmission. However, cases of transmission from within hotel quarantine contributed to Victoria's second wave, and multiple other cases of transmission from within hotel quarantine have been observed since in Australia. Accordingly, the model allows the generation of community infected cases from within hotel quarantine with a (very low) daily probability $\mathrm{P}_{\mathrm{Q}}$.

All the models used in this study assume homogeneous mixing of infected with a susceptible pool of size SUS. The number of susceptible people, POP, is initially set to 20 million, assuming approximately $80 \%$ of the Australian population was initially susceptible. New infected cases are subtracted daily from SUS, and the daily transmission rate is multiplied by the fraction (1-SUS/POP). Given the small size of Australian outbreaks to date, the reduction in the susceptible pool size has negligible effect on transmission rates in the simulations presented here.

\section{Parameter uncertainty and Bayesian inference}

The model suite has 24 model parameters (Table 1). In JulyAugust 2020, when this study was undertaken, many of these parameters, particularly those related to the natural history of the disease, were considered to be well-constrained by prior knowledge. But others, particularly those defining the effectiveness of Australian control measures, were poorly constrained. We wanted to understand the capacity of the model to reproduce Australian observations of daily cases prior to that time, and the extent to which those observations could constrain the uncertain parameters, so as to reduce uncertainty in model simulations of responses to future control measures.

A Monte Carlo Bayesian inference procedure was, therefore, undertaken to fit the model to Australian observations obtained from https://www.covid19data.com.au/ and https:// www.worldometers.info/coronavirus/\#countries for the period 20 February to 5 July 2020 , noting that estimation was completed 6 August.

A simple sample importance resample (SIR) procedure was used to obtain the posterior distribution of parameters. An ensemble of 200,000 simulations was generated, using independent random samples from the prior parameter distribution (the prior was treated as uniform on the parameter ranges specified in Table 1, and parameters were treated as independent in the prior). Because of the large ensemble size, the DCM was used as a fast approximation to the SCM in this procedure. Comparison of posterior ensembles from the SCM and DCM suggested this provided a good approximation to the posterior parameter distribution for both models. Both SCM and DCM were able to reproduce the observed time series well. (See Appendix 2 for detailed methods and results.)

Table 1 gives the maximum likelihood values of the uncertain parameters. The inference procedure yielded a large (10,000 member) random sample from the posterior parameter distribution. In the model scenarios described below, parameters for each simulation were drawn randomly from this posterior sample. This allowed us to represent the uncertainty in model predictions due to residual parameter uncertainty, as well as the uncertainty arising from stochastic events within the model itself.

\section{Model scenarios}

Mandated social distancing measures were reintroduced on 9 July 2020 in Victoria, as rapidly growing daily case numbers reached a weekly average of 100 . Model simulation scenarios (Table 2) were designed to assess the effectiveness of implementing different levels of social distancing at that trigger level. Social distancing levels in these scenarios are defined by the control variable $\mathrm{SD}=(\mathrm{G} 0-\mathrm{G}) /(\mathrm{G} 0-\mathrm{GLD})$, so $\mathrm{SD}=0$ corresponds to no social distancing, and $\mathrm{SD}=1$ corresponds to the lockdown obtaining in April 2020.

For each simulated SD level, from 0.5 to 1.0 , mandated measures remain in place for a minimum 40-day period and then social distancing is relaxed in a linear fashion over 
Table 1 Model parameters, prior values, and prior ranges and maximum likelihood values for those parameters subject to

Bayesian inference

\begin{tabular}{|c|c|c|c|}
\hline Symbol & Description & $\begin{array}{l}\text { Prior } \\
\text { value(s) }\end{array}$ & $\begin{array}{l}\text { Maximum likelihood } \\
\text { value }\end{array}$ \\
\hline $\mathrm{T}_{\mathrm{S}}$ & Days to onset of symptoms & 5 days & \\
\hline $\mathrm{T}_{\mathrm{I}}$ & Days to onset of infectivity & 4 days & \\
\hline $\mathrm{T}_{\mathrm{F}}$ & Days to cessation of infectivity & 8 days & \\
\hline $\mathrm{T}_{\mathrm{H}}$ & Days to develop severe symptoms & 10 days & \\
\hline $\mathrm{T}_{\mathrm{D}}$ & Days to first deaths & 12 days & \\
\hline $\mathrm{T}_{\mathrm{R}}$ & Days to first recovery & 19 days & \\
\hline $\mathrm{T}_{\mathrm{M}}$ & Maximum period cases are active & 40 days & \\
\hline $\mathrm{P}_{\mathrm{A}}$ & Probability cases are asymptomatic & {$\left[\begin{array}{ll}0.1 & 0.4\end{array}\right]$} & 0.32 \\
\hline $\mathrm{P}_{\mathrm{H}}$ & Probability of hospitalisation for symptomatic cases & 0.1 & \\
\hline $\mathrm{P}_{\mathrm{M}}$ & Probability of death among hospitalised cases & 0.11 & \\
\hline $\mathrm{P}_{\mathrm{D}}$ & Daily probability fatally ill die after TD & 0.15 & \\
\hline $\mathrm{P}_{\mathrm{R}}$ & Daily probability of recovery after TR & 0.2 & \\
\hline G0 & Daily transmission rate before social distancing & {$\left[\begin{array}{ll}0.3 & 0.65\end{array}\right]$} & 0.5 \\
\hline $\mathrm{G}_{\mathrm{LD}}$ & $\begin{array}{l}\text { Daily transmission rate at peak of March-April } \\
\text { lockdown }\end{array}$ & {$\left[\begin{array}{lll}0.05 & 0.25\end{array}\right]$} & 0.11 \\
\hline RSD & Relaxation of social distancing $=\left(\mathrm{G}-\mathrm{G}_{\mathrm{LD}}\right) /\left(\mathrm{G} 0-\mathrm{G}_{\mathrm{LD}}\right)$ & {$\left[\begin{array}{ll}0.7 & 1.0\end{array}\right]$} & 0.98 \\
\hline $\mathrm{F}_{\mathrm{A}}$ & Ratio of asymptomatic to symptomatic transmission & {$\left[\begin{array}{ll}0.1 & 0.4\end{array}\right]$} & 0.19 \\
\hline $\mathrm{P}_{\mathrm{DC}}$ & Daily probability of detection in community & {$\left[\begin{array}{ll}0.2 & 0.5\end{array}\right]$} & 0.36 \\
\hline $\mathrm{P}_{\mathrm{DSQ}}$ & Daily probability of detection in self-isolation & 0.8 & \\
\hline $\mathrm{P}_{\mathrm{T}}$ & Daily probability of tracing downstream contacts & {$\left[\begin{array}{ll}0.2 & 0.8\end{array}\right]$} & 0.24 \\
\hline $\mathrm{P}_{\mathrm{L}}$ & $\begin{array}{l}\text { Daily probability of transmission from self-isolated } \\
\text { cases }\end{array}$ & {$\left[\begin{array}{ll}0.1 & 0.3\end{array}\right]$} & 0.11 \\
\hline $\mathrm{P}_{\mathrm{U}}$ & Fraction of community hidden/uncooperative & {$\left[\begin{array}{ll}0.1 & 0.6\end{array}\right]$} & 0.39 \\
\hline $\mathrm{P}_{\mathrm{Q}}$ & Daily probability of quarantine breakdown & 0.0 to 0.01 & 0 \\
\hline POP & Total population size & $20,000,000$ & \\
\hline TCAP & Maximum tracing capacity in daily new cases & $100-500$ & 500 \\
\hline
\end{tabular}

60 days. These scenarios assume highly effective border controls and quarantine for all new arrivals into Australia and $\mathrm{P}_{\mathrm{Q}}$ is set to zero. Social distancing is not relaxed until there is no recorded community transmission. Thus, each of the six scenarios in Table 2 assumes the goal is to achieve no community transmission.

Table 2 Median (2.5\%-97.5 CI) values of additional Elimination days and Social distancing days (sum of social distancing level each day for 365 days) and number of COVID-19 deaths and associated (based on median values) Economy costs of social distancing, Value of statistical

\begin{tabular}{lllllll}
\hline Social distancing level & 0.5 & 0.6 & 0.7 & 0.8 & 0.9 \\
\hline Elimination days (\#) & $360(279-366)$ & $366(366-366)$ & $249(134-366)$ & $118(66-190)$ & $73(50-107)$ & $51(37-75)$ \\
Social distancing days (\#) & $183(155-183)$ & $220(220-220)$ & $196(116-256)$ & $117(78-177)$ & $94(75-125)$ & $83(71-107)$ \\
Economy costs of social distancing (billion \$) & 38.43 & 46.2 & 41.16 & 24.57 & 19.74 \\
COVID-19 deaths (\#) & $77,020(53,822-104,277)$ & 28,058 & 267 & 135 & 101 \\
& & $(448-69,931)$ & $(135-1151)$ & $(80-216)$ & $(68-139)$ & $(66-115)$ \\
Value of statistical lives lost (\$ billion) & 377.40 & 137.48 & 1.31 & 0.66 & 0.49 & 0.42 \\
\hline
\end{tabular}

1. Economy costs of social distancing $=\$ 210$ million per social distance day.

2. Value of statistical life $=\$ 4.9$ million.

3. Elimination days is the number of days until zero community transmission (elimination) is achieved. Elimination days $=366$ means the strategy fails to achieve no community transmission after 365 days
Two suppression scenarios were also simulated (see Table 3). In each suppression scenario, stringent social distancing measures $(\mathrm{SD}=1.0)$ are imposed when the weekly average of new daily recorded cases is 100 , but relaxation is triggered by a weekly average of 20 daily recorded cases. In suppression scenario A, social distancing is imposed for a

lives lost and Hospitalisation costs for social distancing levels SD from 0.5 to 1.0 for 365 days after implementation of social distancing when average daily cases over the preceding 7 days exceeds 100 
Table 3 Median (2.5\%-97.5 CI) values of additional Social distancing days (sum of social distancing level each day for 365 days) and number of COVID-19 deaths and associated (based on median values) Economy costs of social distancing, Value of statistical lives lost and Hospitalisation costs for social distancing level $=1.0$ for 365 days after implementation of social distancing

\begin{tabular}{lll}
\hline & Suppression scenario A & Suppression scenario B $^{3}$ \\
\hline Social distancing days (\#) & $101(71-210)$ & $115(52-225)$ \\
Economy costs of social distancing (billion \$) & 21.21 & 24.15 \\
COVID-19 deaths (\#) & $124(66-261)$ & $190(67-411)$ \\
Value of statistical lives lost (\$ billion) & 0.61 & 0.93 \\
\hline
\end{tabular}

1. Economy costs of social distancing $=\$ 210$ million per social distance day.

2. Value of statistical life $=\$ 4.9$ million.

3. Social distancing is implemented for 40 days after which gradual relaxation over 60 days occurs once the weekly average of new daily recorded cases declines to 20 .

4. No minimum of 40 days of social distancing; gradual relaxation over 60 days occurs once the weekly average of new daily recorded cases declines to 20

minimum of 40 days before the relaxation criteria is assessed, while in suppression scenario $\mathrm{B}$, there is no minimum period. For both scenarios, once the relaxation criteria are met, gradual relaxation to zero social distancing occurs over a 60-day period. In each scenario, border quarantine leakage (failure) occurs with a daily probability of $0.2 \%$ per infected arrival from overseas $\left(\mathrm{P}_{\mathrm{Q}}=0.002\right)$.

For each of these scenarios, the SCM was used to generate an ensemble of 1000 runs, drawing parameter sets randomly from the posterior distribution produced by the Bayesian inference procedure described above. The simulated ensemble outputs were statistically analysed and daily percentiles calculated.

\section{Economy costs}

Economy-wide costs of the national and high stringency social distancing that began in March 2020 are based on Australian Bureau of Statistics (ABS) data at a Victorian level equivalent to approximately $\$ 210$ million per lockdown day (Kompas et al. 2020). Economy costs of a lockdown were assumed to be linear in the different levels of mandated social distancing, noting that greater social distancing and an increased frequency of cycles of high stringency social distancing followed by relaxation are likely to more than proportionally increase economy costs. COVID-19 related fatalities are valued at $\$ 4.9$ million per value of statistical life (VSL), sourced from Prime Minister and Cabinet (Prime Minister and Cabinet 2020).

\section{Results and discussion}

\section{Effects of social distancing stringency in elimination scenarios}

Results are provided in Table 2 for a period of 365 days following initial implementation of different levels of SD, assuming no leakage from hotel quarantine. Stringent social distancing, $(\mathrm{SD}=1.0)$, results in elimination of community transmission after approximately 50 days (median), and within 80 days for every simulation (Fig. 2). By comparison, moderate social distancing $(\mathrm{SD}=0.7)$ takes some 250 days (median) to achieve community elimination and $21 \%$ of simulations fail to eliminate community transmission within one year. Stringent social distancing $(\mathrm{SD}=1)$ results in economy costs of $\$ 17.4 \mathrm{~B}$ compared to $\$ 41.2 \mathrm{~B}$ with $\mathrm{SD}=0.7$. (Table 1 , Fig. 2). The scenarios with weaker social distancing (SD of 0.5 and 0.6 ) result in uncontrolled COVID-19 outbreaks. For SD of 0.5 , some ensemble members achieve elimination within 365 days through herd immunity but at the loss of between 54,000 and 104,000 lives (Table 1).

\section{Effect of relaxation rules in suppression scenarios}

Figure 3a,b compares the simulated daily new cases (median, quartiles, 5-95 percentiles from a 1000 member ensemble) with observations for suppression scenario A (with a minimum 40 days implementation of social distancing) and suppression scenario $\mathrm{B}$ without a minimum duration constraint. For suppression scenario A, elimination of community transmission is achieved in more than $75 \%$ of ensemble members, and the ensemble median achieves and maintains elimination within 100 days (Table 3 ). For suppression scenario B, there is a greater than $50 \%$ chance of a second outbreak requiring reimposition of social distancing, and a greater than $25 \%$ chance of further cycles of outbreak and social distancing (Fig. 3b). The median time to community elimination is twice that for suppression scenario A (Table 3).

Even for suppression scenario A, more than $5 \%$ of the ensemble members display continuing outbreaks. The seeding of new infectives by rare and random failures of hotel quarantine $\left(\mathrm{P}_{\mathrm{Q}}=0.002\right)$ may contribute, but the quasi-cyclic nature of these outbreaks suggests there is a small but non-zero risk that relaxation after 40 days, at a trigger level of 20 daily cases, 
Fig. 2 a Community elimination: $\mathrm{SD}=1.0($ day 35$)$, trigger $=100$ daily cases, $\mathrm{P}_{\mathrm{Q}}=0$. b Community elimination: $\mathrm{SD}=0.7$ (day 35), trigger $=100$ daily cases, $\mathrm{P}_{\mathrm{Q}}=0$. N.B: Simulations (median, quartiles, 5-95 percentiles) are from a 1000 members ensemble and observed daily new local Australian cases for SD levels. Median (thick line), quartiles (thin lines), 5-95 percentiles (dashed lines), observed daily new Australian local cases, 6 June to 15 July $2020(*)$
A Community elimination: $\mathrm{SD}=1.0($ day 35$)$, trigger $=100$ daily cases, $\mathrm{P}_{\mathrm{Q}}=0$.

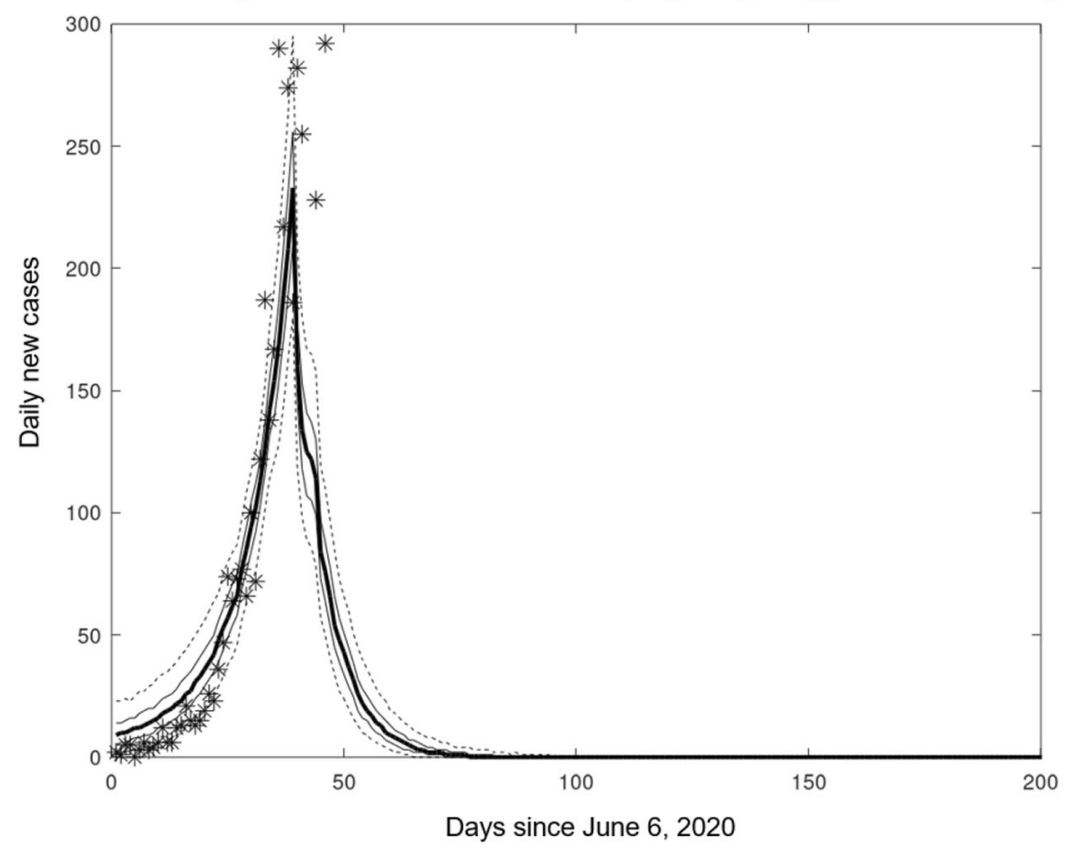

B Community elimination: $\mathrm{SD}=0.7$ (day 35), trigger $=100$ daily cases, $\mathrm{P}_{\mathrm{Q}}=0$.

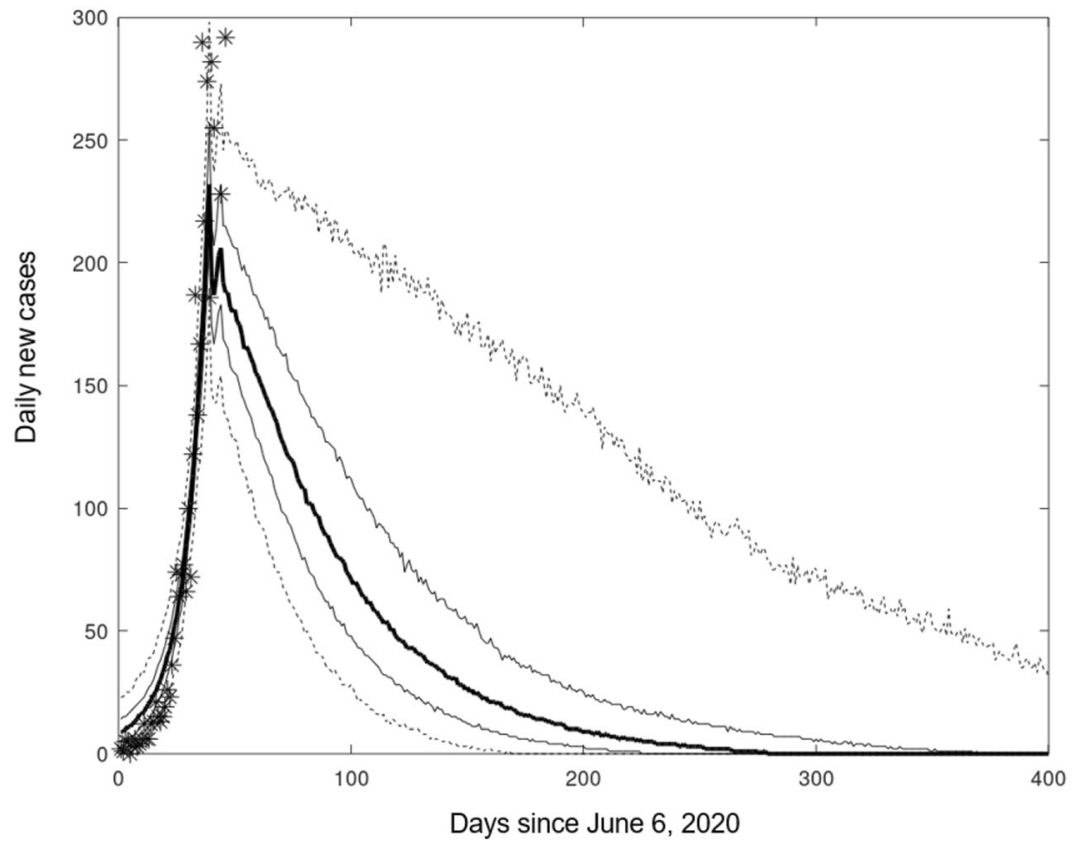

fails to achieve community elimination. This risk is clearly much greater for suppression scenario B, which allows relaxation of social distancing within 40 days.

\section{Limitations of this study}

Our model suite does not allow us to fully capture the differences in transmission across multiple communities or subpopulations as would an agent-based model. Such transmission differences may arise from multiple factors, including cultural reasons, housing density, and the proportion of workers who are in the casual workforce and who may have financial incentives not to be tested or go to work sick.

The relationship between hidden transmission and essential workers, not accounted for in our modelling, is relevant for the effectiveness of social distancing. This is because, depending on the stringency of social distancing measures, workers may still be able to infect their workmates at their workplaces. In 
Fig. 3 a Scenario A: $\mathrm{SD}=1.0$, suppression (40 days minimum) \& relaxation triggers $100 \& 20$. b Scenario B: SD = 1.0 (day 35), suppression \& relaxation triggers $100 \& 20$. N.B. Ensemble percentiles: median (thick line), quartiles (thin lines), 5-95 percentiles (dashed lines), observed daily new Australian local cases, 6 June to 15 July 2020 (*). Triggers defined by daily cases. SD begins at day 35 . Quarantine leakage, $P_{Q}=0.002$ in $2 \mathrm{a}$ and $2 \mathrm{~b}$
A Scenario A: $\mathrm{SD}=1.0$, suppression (40 days minimum) \& relaxation triggers $100 \& 20$.

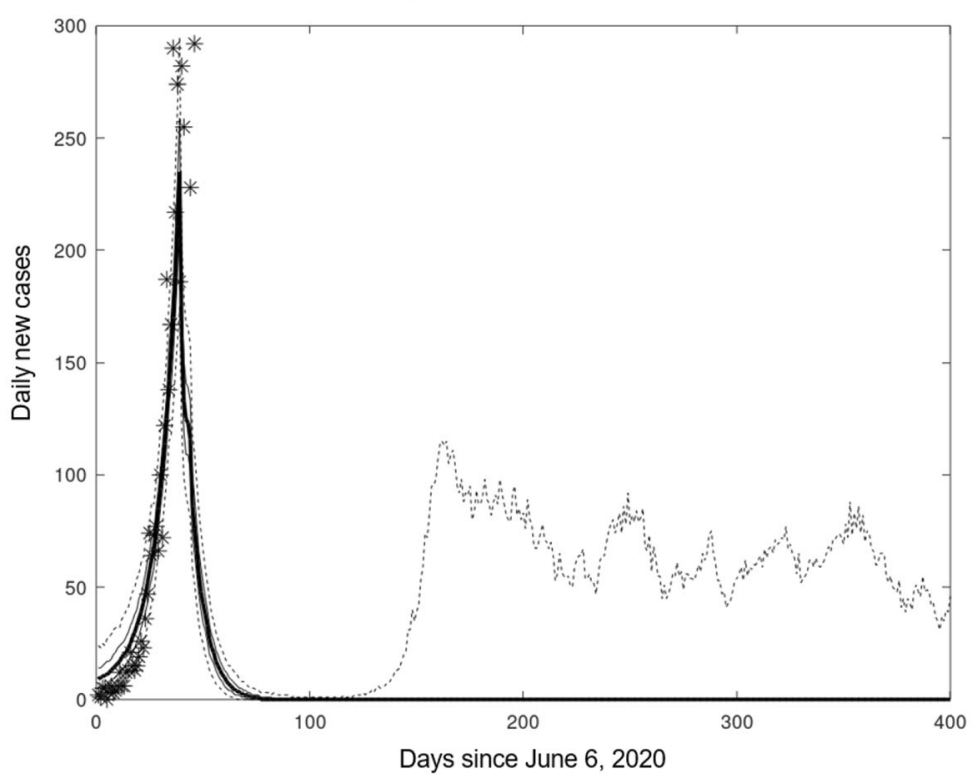

B Scenario B: $\mathrm{SD}=1.0($ day 35$)$, suppression $\&$ relaxation triggers $100 \& 20$.

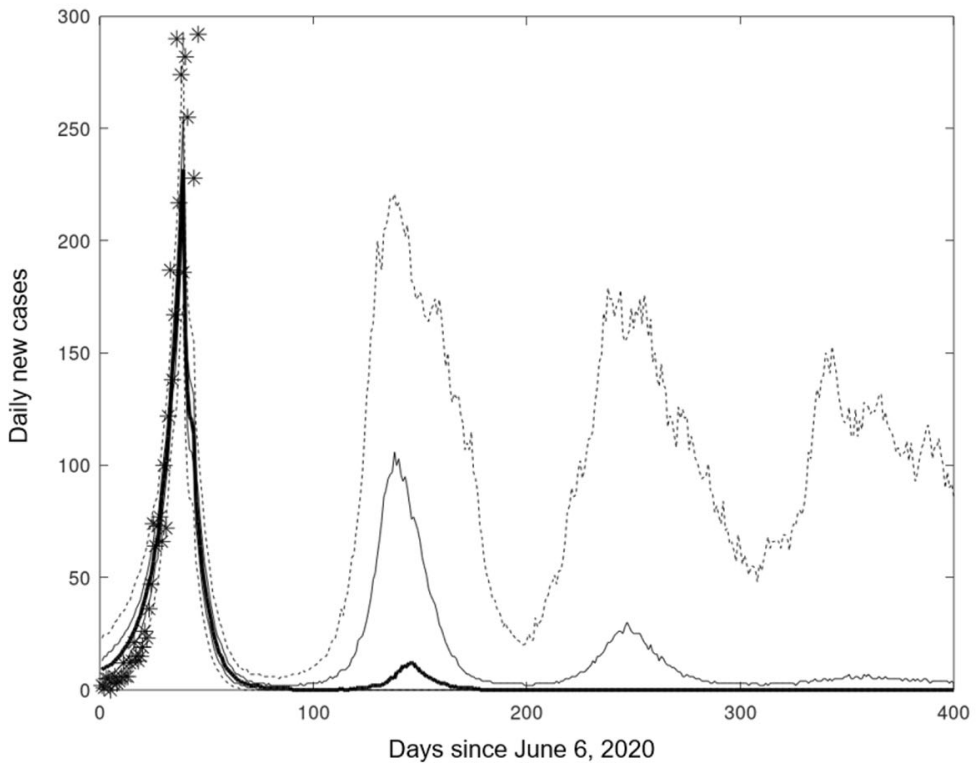

recognition of this incentive problem, supplementary payments of $\mathrm{A} \$ 1500$ were provided to Victorian workers from 20 June 2020 who tested positive or who were a close contact to someone who tested positive, and from 13 August, $A \$ 450$ was provided to those who were in self-isolation awaiting test results.

\section{Conclusions}

Our results provide robust support for a highly stringent suppression strategy in relation to COVID-19 infections in
Australia. We find: one, that better public health outcomes (reduced COVID-19 fatalities) are positively associated with lower economy costs and higher levels of social distancing; two, achieving zero community transmission lowers both public health and economy costs compared to allowing community transmission to continue; three, early relaxation of social distancing, and in particular in the absence of a minimum social distancing period (minimum 40 days) and with quarantine leakage, increases both public health and economy costs; four, our simulated local cases using data until 17 July, are comparable to the actual suppression of COVID-19 in Victoria after 5 August that had the implicit goal of 
community elimination and gradually relaxed SD measures at pre-defined thresholds.

If the goal of social distancing is to achieve zero community transmission (elimination), as in the State of Victoria, SD levels of $0.8,0.9$ and 1.0, achieve elimination with a $100 \%$ probability over the 365 days. SD levels of 0.5 and 0.6 fail to achieve community elimination within the simulation period. A SD level of 0.7 achieves elimination within 365 days in approximately $80 \%$ of simulations. Lower levels of SD increase both COVID-19 fatalities and economy costs. This finding is consistent with an agent-based model for Victoria that compares a standard lockdown (with and without masks) with a more severe lockdown (Blakely et al. 2020) and a national model developed for the first wave of COVID-19 infections in Australia (Chang et al. 2020).

If suppression (rather than elimination of community transmission) is the goal, such that relaxation of social distancing measures begins at a threshold relating to the weekly average of new daily recorded cases, then lower costs are incurred when social distancing is imposed for a minimum period that is sufficiently long. Imposing a binding minimum number of social distancing days per lockdown reduces the total days in lockdown over a 12-month period and, thus, the associated economy costs.

\section{Appendix 1}

\section{Detailed model formulation}

The individual-based model (IBM) represents individual infected cases, which are assigned a unique sequential ID. Changes in the status of each case are recorded as changes in an array of quality attributes attached to each ID. The stochastic compartment model (SCM) represents numbers of individual cases in daily cohorts of newly infected people. It indexes daily cohorts by the day d they were infected. The SCM must represent changes in status by dividing each daily cohort into a set of labelled sub-compartments, with one subcompartment for each meaningful and feasible combination of attributes. Changes in the status of individuals with respect to disease progression, detection, contact tracing and quarantine are recorded by transferring appropriate number of individuals between sub-compartments.

The sub-compartments and associated labels for the SCM are given in Table 4. These are sub-compartments of daily cohorts; for example, for label SF, $\mathrm{X}_{\mathrm{SF}}(\mathrm{t}, \mathrm{d})$ is the number of cases in sub-compartment SF on day $t$ within the cohort infected on day $\mathrm{d}$. The two exceptions are the compartments for the dying and recovering: these are pooled across daily cohorts; therefore, $\mathrm{X}_{\mathrm{FI}}(\mathrm{t})$ and $\mathrm{X}_{\mathrm{RD}}(\mathrm{t})$ represent the total number of individuals across all relevant cohorts who are respectively dying or recovering on day $t$.

The DCM has the same sub-compartments as the SCM. The numbers of individuals in sub-compartments in the SCM are integers, and transfers between sub-compartments are determined by drawing integer numbers from appropriate probability distributions. In contrast, the numbers in subcompartments in the DCM are rational numbers, and transfers are computed based on expected fractions.

The transitions in status associated with disease progression, detection, contact tracing and quarantine are described qualitatively in the body of the paper. For the most part, the implementation of these as transfers between subcompartments in the SCM is straightforward. Whenever a set of $\mathrm{X}$ individuals each face a probability $\mathrm{P}$ of change in status the model transfers DX individuals to the corresponding sub-compartment, with DX drawn from a binomial distribution with parameters $\mathrm{X}$ and $\mathrm{P}$. If there are more than two possible outcomes, a multinomial distribution is used. The equations and conditions for probabilistic transfers among sub-compartments are spelt out in detail in Table 5, with the exceptions of transmission and source detection. These are implemented as follows.

\section{Transmission}

Daily infections per individual are assumed to have a negative binomial distribution with mean $\mathrm{G}$ and dispersion parameter $\mathrm{k}$ '. Total infections per individual over an infectious period $\mathrm{T}_{\mathrm{L}}$ $\left(=T_{F}+1-T_{I}\right)$ will then be negative binomial with mean G. $T_{L}$,

Table 4 Sub-compartments within daily cohorts in the SCM

\begin{tabular}{ll}
\hline Label & Description \\
\hline SF & Symptomatic/pre-symptomatic in community \\
AF & Asymptomatic in community \\
SU & Hidden symptomatic/pre-symptomatic \\
AU & Hidden asymptomatic \\
ST & Traceable symptomatic/pre-symptomatic in community \\
AT & Traceable asymptomatic in community \\
SSQ & Symptomatic/pre-symptomatic in self-quarantine \\
ASQ & Asymptomatic in self-quarantine \\
D & Detected (symptomatic) cases \\
SFO & Overseas pre-symptomatic in community \\
SSQO & Overseas pre-symptomatic in self-quarantine \\
SQ & Overseas symptomatic/pre-symptomatic in hotel quarantine \\
AQ & Overseas asymptomatic in hotel quarantine \\
SH & Hospital patients \\
FI & Fatally ill hospital patients \\
M & Dead \\
RD & Recovering detected cases \\
\hline
\end{tabular}


and dispersion coefficient $\mathrm{k}=\mathrm{k}^{\prime} \cdot \mathrm{T}_{\mathrm{L}}$. The sum of daily new infections from XI sources is then negative binomial with mean G.XI and dispersion coefficient $\mathrm{k}^{\prime}$.XI. It has been reported that total infections per individual are highly overdispersed; therefore, $\mathrm{k}$ is set to 0.2 . This means that most infected individuals infect no-one, while rare super-spreaders can infect 30 or more.

The number of potentially infectious sources on day $t$ is obtained by summing cases from all potentially infectious cohorts $X(t, d)$ with $T_{I}<=t-d<=T_{F}$. These sources need to be divided into five classes, according to their contributions to transmission:

- Free symptomatic sources:

$\mathrm{S}_{\mathrm{SF}}(\mathrm{t})=\sum_{\mathrm{d}}\left\{\mathrm{X}_{\mathrm{SF}}(\mathrm{t}, \mathrm{d})+\mathrm{X}_{\mathrm{SU}}(\mathrm{t}, \mathrm{d})+\mathrm{X}_{\mathrm{ST}}(\mathrm{t}, \mathrm{d})+\mathrm{X}_{\mathrm{SO}}(\mathrm{t}, \mathrm{d})\right\}$, for $\mathrm{T}_{\mathrm{I}}<=\mathrm{t}-\mathrm{d}<=\mathrm{T}_{\mathrm{F}} ;$

- Self-quarantined symptomatic sources:

$$
\begin{aligned}
\mathrm{S}_{\mathrm{SSQ}}(\mathrm{t}) & =\sum_{\mathrm{d}}\left\{\mathrm{X}_{\mathrm{SSQ}}(\mathrm{t}, \mathrm{d})+\mathrm{X}_{\mathrm{SSQO}}(\mathrm{t}, \mathrm{d})\right\}, \text { for } \mathrm{T}_{\mathrm{I}}< \\
& =\mathrm{t}-\mathrm{d}<=\mathrm{T}_{\mathrm{F}} ;
\end{aligned}
$$

- Free asymptomatic sources:

$$
\begin{aligned}
\mathrm{S}_{\mathrm{AF}}(\mathrm{t}) & =\sum_{\mathrm{d}}\left\{\mathrm{X}_{\mathrm{AF}}(\mathrm{t}, \mathrm{d})+\mathrm{X}_{\mathrm{AU}}(\mathrm{t}, \mathrm{d})+\mathrm{X}_{\mathrm{AT}}(\mathrm{t}, \mathrm{d})\right\}, \text { for } \mathrm{T}_{\mathrm{I}} \\
& <=\mathrm{t}-\mathrm{d}<=\mathrm{T}_{\mathrm{F}} ;
\end{aligned}
$$

- Self-quarantined symptomatic sources:

$$
\mathrm{S}_{\mathrm{ASQ}}(\mathrm{t})=\sum_{\mathrm{d}} \mathrm{X}_{\mathrm{ASQ}}(\mathrm{t}, \mathrm{d}), \text { for } \mathrm{T}_{\mathrm{I}}<=\mathrm{t}-\mathrm{d}<=\mathrm{T}_{\mathrm{F}} .
$$

- Self-isolating detected sources:

$$
\mathrm{S}_{\mathrm{D}}(\mathrm{t})=\sum_{\mathrm{d}} \mathrm{X}_{\mathrm{D}}(\mathrm{t}, \mathrm{d}), \text { for } \mathrm{T}_{\mathrm{I}}<=\mathrm{t}-\mathrm{d}<=\mathrm{T}_{\mathrm{F}} .
$$

These sources are then weighted appropriately to calculate their expected contribution to transmission. Contributions from cases in self-isolation and self-quarantine at home are multiplied by the proportion $\mathrm{P}_{\mathrm{L}}$ that breach self-isolation/ self-quarantine. Contributions from asymptomatic community cases are multiplied by $\mathrm{F}_{\mathrm{A}}$. These scaled contributions are then summed to produce an infectious potential on day $\mathrm{t}, \mathrm{XI}(\mathrm{t})$ :

$$
\begin{aligned}
\mathrm{XI}(\mathrm{t})= & \mathrm{S}_{\mathrm{SF}}(\mathrm{t})+\mathrm{P}_{\mathrm{L}} \cdot \mathrm{S}_{\mathrm{SSQ}}(\mathrm{t})+\mathrm{P}_{\mathrm{L}} \cdot \mathrm{S}_{\mathrm{D}}(\mathrm{t})+\mathrm{F}_{\mathrm{A}} \cdot \mathrm{S}_{\mathrm{AF}}(\mathrm{t}) \\
& +\mathrm{F}_{\mathrm{A}} \cdot \mathrm{P}_{\mathrm{L}} \cdot \mathrm{S}_{\mathrm{ASQ}}(\mathrm{t}) .
\end{aligned}
$$

\section{Contact tracing}

On day $t$, the cohort $\mathrm{X}(\mathrm{t}, \mathrm{d})$ infected on day $\mathrm{d}$ has potential source cohorts $X\left(t, d_{1}\right)$ with $T_{I}<=d-d_{1}<=T_{F}$. When the new cohort is formed on day $\mathrm{d}$, the model computes and stores the total number of self-quarantining symptomatic sources
$\mathrm{S}_{\mathrm{SSQ}}(\mathrm{d})$, and the total number of detected sources $\mathrm{S}_{\mathrm{D}}(\mathrm{d})$, summed over these potential source cohorts. On subsequent days $t$, the same calculation can be done over the updated source cohorts $X\left(t, d_{1}\right)$, to produce $S_{S S Q}(t, d), S_{D}(t, d)$. Because detection is a random process in the SCM, we do not know exactly how many of the intervening detections, $S_{D}(t, d)-S_{D}(d)$, come from self-quarantined sources vs free sources. However, given self-isolated symptomatic cases are detected with high probability, it is a reasonable approximation to assume the additional detections come first from the self-quarantined symptomatic source pool on day d, $\mathrm{S}_{\mathrm{SSQ}}(\mathrm{d})$, and after that from the free source pool. The decreases in selfquarantined sources and free sources from day $d$ to day $t$ are then given by:

$$
\begin{aligned}
& \operatorname{DEL}_{S Q}(t, d)=\min \left\{S_{S S Q}(d), S_{D}(t, d)-S_{D}(d)\right\} \cdot D_{D E L}(t, d) \\
& \quad=S_{D}(t, d)-S_{D}(d)-D E L_{S Q}(t, d) .
\end{aligned}
$$

The reduction in infectious potential since $\mathrm{d}$ is then:

$\operatorname{DEL}_{X I}(t, d)=\operatorname{DEL}_{\mathrm{F}}\left(t_{0}, d\right)+P_{L} \cdot \operatorname{DEL}_{\mathrm{SQ}}(t, d)$.

The fraction of cohort $\mathrm{X}(\mathrm{t}, \mathrm{d})$ subject to downstream contact tracing on day $t$ should then be:

$\mathrm{FT}(\mathrm{t}, \mathrm{d})=\operatorname{DEL}_{\mathrm{XI}}(\mathrm{t}, \mathrm{d}) / \mathrm{XI}(\mathrm{d})$.

Individuals are moved incrementally from free to traceable compartments in each daily update. The fraction moved each day should be proportional to the daily increase in the traceable fraction, $\mathrm{FT}(\mathrm{t}, \mathrm{d})-\mathrm{FT}(\mathrm{t}-1, \mathrm{~d})$, with $\mathrm{FT}(\mathrm{d}, \mathrm{d})=0$. The number to be moved is calculated as a proportion of the number remaining. Thus, the fraction moved each day from AF to AT and SF to ST is:

$\mathrm{FM}=(\mathrm{FT}(\mathrm{t}, \mathrm{d})-\mathrm{FT}(\mathrm{t}-1, \mathrm{~d})) /(1-\mathrm{FT}(\mathrm{t}-1, \mathrm{~d}))$, provided $\mathrm{FT}(\mathrm{t}-1, \mathrm{~d})<1,=0$ if $\mathrm{FT}(\mathrm{t}-1, \mathrm{~d})=1$.

The numbers moved each day are DXST $=\mathrm{FM} \cdot \mathrm{XSF}(\mathrm{t}, \mathrm{d})$, DXAT $=$ FM.XAF $(d, t)($ The SCM deals in integer numbers of cases;therefore, DXST and DXAT are rounded to the nearest integer. If either is less than 1 , it is set to 1 with probability DXST or DXAT, zero otherwise).

\section{Appendix 2}

\section{Bayesian Inference}

\section{Inference Methods}

Australian observations were obtained from https://www. covid19data.com.au/ and https://www.worldometers.info/ coronavirus/\#countries for the period 20 February to 5 July 2020, noting that estimation was completed 6 August. 
Table 5 Sub-compartment exchanges in SCM, in order of execution in each daily time step

\begin{tabular}{|c|c|c|}
\hline Process & $\begin{array}{l}\text { Daily } \\
\text { cohorts }\end{array}$ & Compartment exchanges \\
\hline Transmission & $\begin{array}{l}\mathrm{T}_{\mathrm{I}}<=\mathrm{d}<= \\
\mathrm{T}_{\mathrm{F}}\end{array}$ & See Text. \\
\hline Asymptomatic \& hidden & $\mathrm{d}=0$ & $\begin{array}{l}\text { Given } \mathrm{X} \text { new local cases: }\left[\mathrm{X}_{\mathrm{SF}}, \mathrm{X}_{\mathrm{AF}}, \mathrm{X}_{\mathrm{SU}}, \mathrm{X}_{\mathrm{AU}}\right] \text { is } \sim \text { multinomial }\left(\mathrm{X},\left[\left(1-\mathrm{P}_{\mathrm{A}}\right) \cdot\left(1-\mathrm{P}_{\mathrm{U}}\right), \mathrm{P}_{\mathrm{A}} \cdot\left(1-\mathrm{P}_{\mathrm{U}}\right), \mathrm{P}_{\mathrm{U}}\left(1-\mathrm{P}_{\mathrm{A}}\right) \text {, }\right.\right. \\
\left.\left.\mathrm{P}_{\mathrm{A}} \cdot \mathrm{P}_{\mathrm{U}}\right]\right)\end{array}$ \\
\hline Overseas arrivals & $\mathrm{d}=0$ & $\begin{array}{l}\text { Overseas reported (symptomatic) cases } \mathrm{XSO} \text { treated as newly infected } \mathrm{T}_{\mathrm{S}} \text { days earlier. Matched by } \\
\text { asymptomatic cases } \mathrm{XAO} \sim \mathrm{BIN}\left(\mathrm{XSO}, \mathrm{P}_{\mathrm{A}} /\left(1-\mathrm{P}_{\mathrm{A}}\right)\right) \text {. For arrivals: } \\
\text { Before March 17: } \mathrm{X}_{\mathrm{SFO}}=\mathrm{XSO}, \mathrm{X}_{\mathrm{AF}}=\mathrm{X}_{\mathrm{AF}}+\mathrm{XAO} \text {. } \\
\text { From March } 17 \text { to March } 28: \mathrm{X}_{\mathrm{SSQO}}=\mathrm{XSO}, \mathrm{X}_{\mathrm{ASQ}}=\mathrm{XAO} \text {. } \\
\text { After March 28: } \mathrm{X}_{\mathrm{SQ}}=\mathrm{XSO}, \mathrm{X}_{\mathrm{AQ}}=\mathrm{XAO} \text {. }\end{array}$ \\
\hline $\begin{array}{l}\text { Hotel quarantine } \\
\text { breakdown }\end{array}$ & $\mathrm{d}=0$ & $\begin{array}{l}\text { Hotel quarantine evasions } \mathrm{QE} \sim \mathrm{BIN}\left(\mathrm{XSQ}, \mathrm{P}_{\mathrm{Q}}\right) \\
\mathrm{X}_{\mathrm{SQ}}=\mathrm{X}_{\mathrm{SQ}}-\mathrm{QE}, \mathrm{X}_{\mathrm{SU}}=\mathrm{X}_{\mathrm{SU}}+\mathrm{QE} \text {. }\end{array}$ \\
\hline Source detected & $\mathrm{d}>=1$ & $\begin{array}{l}\text { DXST }=\text { additional symptomatic cases with detected sources. DXAT = additional asymptomatic cases with } \\
\text { detected sources. (See text for derivation). } \\
\mathrm{X}_{\mathrm{ST}}=\mathrm{X}_{\mathrm{ST}}+\mathrm{DXST}, \mathrm{X}_{\mathrm{SF}}=\mathrm{X}_{\mathrm{SF}}-\mathrm{DXST} \text {. } \\
\mathrm{X}_{\mathrm{AT}}=\mathrm{X}_{\mathrm{AT}}+\mathrm{DXAT}, \mathrm{X}_{\mathrm{AF}}=\mathrm{X}_{\mathrm{AF}}-\mathrm{DXAT} \text {. }\end{array}$ \\
\hline Contact tracing & $\mathrm{d}>=1$ & $\begin{array}{l}\mathrm{CST} \sim \mathrm{BIN}\left(\mathrm{X}_{\mathrm{ST}}, \mathrm{P}_{\mathrm{T}}\right) . \mathrm{X}_{\mathrm{ST}}=\mathrm{X}_{\mathrm{ST}}-\mathrm{CST}, \mathrm{X}_{\mathrm{SSQ}}=\mathrm{X}_{\mathrm{SSQ}}+\mathrm{CST} \\
\mathrm{CAT} \sim \mathrm{BIN}\left(\mathrm{X}_{\mathrm{AT}}, \mathrm{P}_{\mathrm{T}}\right) . \mathrm{X}_{\mathrm{AT}}=\mathrm{X}_{\mathrm{AT}}-\mathrm{CAT}, \mathrm{X}_{\mathrm{ASQ}}=\mathrm{X}_{\mathrm{ASQ}}+\mathrm{CAT}\end{array}$ \\
\hline $\begin{array}{l}\text { Detection of overseas } \\
\text { cases }\end{array}$ & $\mathrm{d}=\mathrm{T}_{\mathrm{S}}$ & $\begin{array}{l}X_{\mathrm{D}}=\mathrm{X}_{\mathrm{D}}+\mathrm{X}_{\mathrm{SFO}}+\mathrm{X}_{\mathrm{SSQO}}, \mathrm{X}_{\mathrm{SFO}}=0, \mathrm{X}_{\mathrm{SSQO}}=0 \\
\mathrm{YDET}=\mathrm{YDET}+\mathrm{X}_{\mathrm{SFO}}+\mathrm{X}_{\mathrm{SSQO}}+\mathrm{X}_{\mathrm{SQO}}\end{array}$ \\
\hline $\begin{array}{l}\text { Detection of cases in } \\
\text { self-quarantine }\end{array}$ & $\mathrm{d}>=\mathrm{T}_{\mathrm{S}}$ & $\begin{array}{l}\mathrm{DSQ} \sim \mathrm{BIN}\left(\mathrm{X}_{\mathrm{SSQ}}, \mathrm{P}_{\mathrm{DSQ}}\right) \cdot \mathrm{X}_{\mathrm{SSQ}}=\mathrm{X}_{\mathrm{SSQ}}-\mathrm{DSQ}, \mathrm{X}_{\mathrm{D}}=\mathrm{X}_{\mathrm{D}}+\mathrm{DSQ} \\
\mathrm{YDET}=\mathrm{YDET}+\mathrm{DSQ}, \mathrm{YDETL}=\mathrm{YDETL}+\mathrm{DSQ}\end{array}$ \\
\hline $\begin{array}{l}\text { Detection of cases in } \\
\text { community }\end{array}$ & $\mathrm{d}>=\mathrm{Ts}$ & $\begin{array}{l}\mathrm{DSF} \sim \mathrm{BIN}\left(\mathrm{X}_{\mathrm{SF}}, \mathrm{P}_{\mathrm{DC}}\right) . \mathrm{X}_{\mathrm{SF}}=\mathrm{X}_{\mathrm{SF}}-\mathrm{DSF}, \mathrm{X}_{\mathrm{D}}=\mathrm{X}_{\mathrm{D}}+\mathrm{DSF} \\
\mathrm{DST} \sim \mathrm{BIN}\left(\mathrm{X}_{\mathrm{ST}}, \mathrm{P}_{\mathrm{DC}}\right) . \mathrm{X}_{\mathrm{ST}}=\mathrm{X}_{\mathrm{ST}}-\mathrm{DST}, \mathrm{X}_{\mathrm{D}}=\mathrm{X}_{\mathrm{D}}+\mathrm{DST} \\
\mathrm{YDET}=\mathrm{YDET}+\mathrm{DSF}+\mathrm{DST}, \mathrm{YDETL}=\mathrm{YDETL}+\mathrm{DSF}+\mathrm{DST}\end{array}$ \\
\hline Hospitalisation & $\mathrm{d}=\mathrm{T}_{\mathrm{H}}$ & $\begin{array}{l}\text { For each of } X=X_{\mathrm{SF}}, X_{\mathrm{SSQ}}, X_{\mathrm{ST}}, X_{\mathrm{SU}}, X_{\mathrm{D}}, X_{\mathrm{SQ}} \\
\text { DH } \sim \mathrm{BIN}\left(\mathrm{X}, \mathrm{P}_{\mathrm{H}}\right) . \mathrm{X}_{\mathrm{SH}}=\mathrm{X}_{\mathrm{SH}}+\mathrm{DH}, \mathrm{YH}=\mathrm{YH}+\mathrm{DH} . \\
\text { For CC }=\mathrm{SF}, \mathrm{SSQ}, \mathrm{ST}, \mathrm{SU}, \mathrm{D}: \mathrm{X}_{\mathrm{CC}}=\mathrm{X}_{\mathrm{CC}}-\mathrm{DH} . \\
\text { For CC=SF, SSQ, ST, SU: YDET }=\mathrm{YDET}+\mathrm{DH}, \mathrm{YDETL}=\mathrm{YDETL}+\mathrm{DH} .\end{array}$ \\
\hline Fatally ill & $\mathrm{d}=\mathrm{T}_{\mathrm{D}}$ & $\mathrm{DFI} \sim \mathrm{BIN}\left(\mathrm{X}_{\mathrm{SH}}, \mathrm{P}_{\mathrm{M}}\right) \cdot \mathrm{X}_{\mathrm{SH}}=\mathrm{X}_{\mathrm{SH}}-\mathrm{DFI}, \mathrm{X}_{\mathrm{FI}}=\mathrm{X}_{\mathrm{FI}}+\mathrm{DFI}$ \\
\hline Death & $\begin{array}{l}\mathrm{T}_{\mathrm{D}}<=\mathrm{d}<= \\
\mathrm{T}_{\mathrm{M}}\end{array}$ & $\begin{array}{l}\mathrm{DD} \sim \mathrm{BIN}\left(\mathrm{X}_{\mathrm{FI}}, \mathrm{P}_{\mathrm{D}}\right) \cdot \mathrm{X}_{\mathrm{FI}}=\mathrm{X}_{\mathrm{FI}}-\mathrm{DD}, \mathrm{X}_{\mathrm{M}}=\mathrm{X}_{\mathrm{M}}+\mathrm{DD} \\
\mathrm{YM}=\mathrm{YM}+\mathrm{DD}\end{array}$ \\
\hline Recovery & $\begin{array}{l}\mathrm{T}_{\mathrm{C}}<=\mathrm{d}<= \\
\mathrm{T}_{\mathrm{M}}\end{array}$ & $\begin{array}{l}\mathrm{DRD} \sim \mathrm{BIN}\left(\mathrm{X}_{\mathrm{D}}, \mathrm{P}_{\mathrm{R}}\right) \cdot \mathrm{X}_{\mathrm{D}}=\mathrm{X}_{\mathrm{D}}-\mathrm{DRD}, \mathrm{X}_{\mathrm{RD}}=\mathrm{X}_{\mathrm{RD}}+\mathrm{DRD} . \\
\mathrm{DRH} \sim \mathrm{BIN}\left(\mathrm{X}_{\mathrm{SH}}, \mathrm{P}_{\mathrm{R}}\right) \cdot \mathrm{X}_{\mathrm{SH}}=\mathrm{X}_{\mathrm{SH}}-\mathrm{DRH}, \mathrm{X}_{\mathrm{RD}}=\mathrm{X}_{\mathrm{RD}}+\mathrm{DRH} . \\
\mathrm{YRD}=\mathrm{YRD}+\mathrm{DRD}+\mathrm{DRH} .\end{array}$ \\
\hline
\end{tabular}

A simple sample importance resample (SIR) procedure was used to obtain the posterior distribution of parameters. The DCM was run using 200,000 independent random samples from the prior parameter distribution (the prior was treated as uniform on the parameter ranges specified in Table 1, and parameters were treated as independent in the prior). For each model run, a likelihood was calculated based on the SSQ errors between predictions and observations. To reduce any weekly reporting artefacts, and to allow for the DCM's inability to reproduce any stochastic variation in the observations, the time series of observations and predictions were smoothed by a running 7-day average before calculating the SSQ error.

A $\ln (X+10)$ transform was applied to the smoothed predictions and observations before computing the SSQ residuals, to give equal weight to errors at low and high case numbers, and to render the residuals approximately Gaussian. The likelihood was calculated from the SSQ assuming a Gaussian distribution of errors, with the degrees of freedom equal to the number of observations minus the number of parameters all divided by 7 to account for the effects of the 7-day running average. The error variance was estimated from the minimum SSQ corresponding to the maximum likelihood parameter set.

The resulting likelihoods were sorted into descending order, along with the associated parameter vectors, and effectively converted into a lookup table for a sample-based posterior cumulative probability density function. This allowed for straightforward random sampling from the posterior. Approximately 10,000 parameter vectors had non-negligible weight in the posterior.

\section{Inference results}

Percentiles of predicted daily detected local cases, based on an ensemble of 200 DCM trajectories using parameter sets drawn 
Fig. 4 Daily new Australian cases of local origin from 20 February 2020. Observations in black. Percentiles for a posterior ensemble from the DCM: median (blue), quartiles (red), 2.5 and 97.5 percentiles (green)

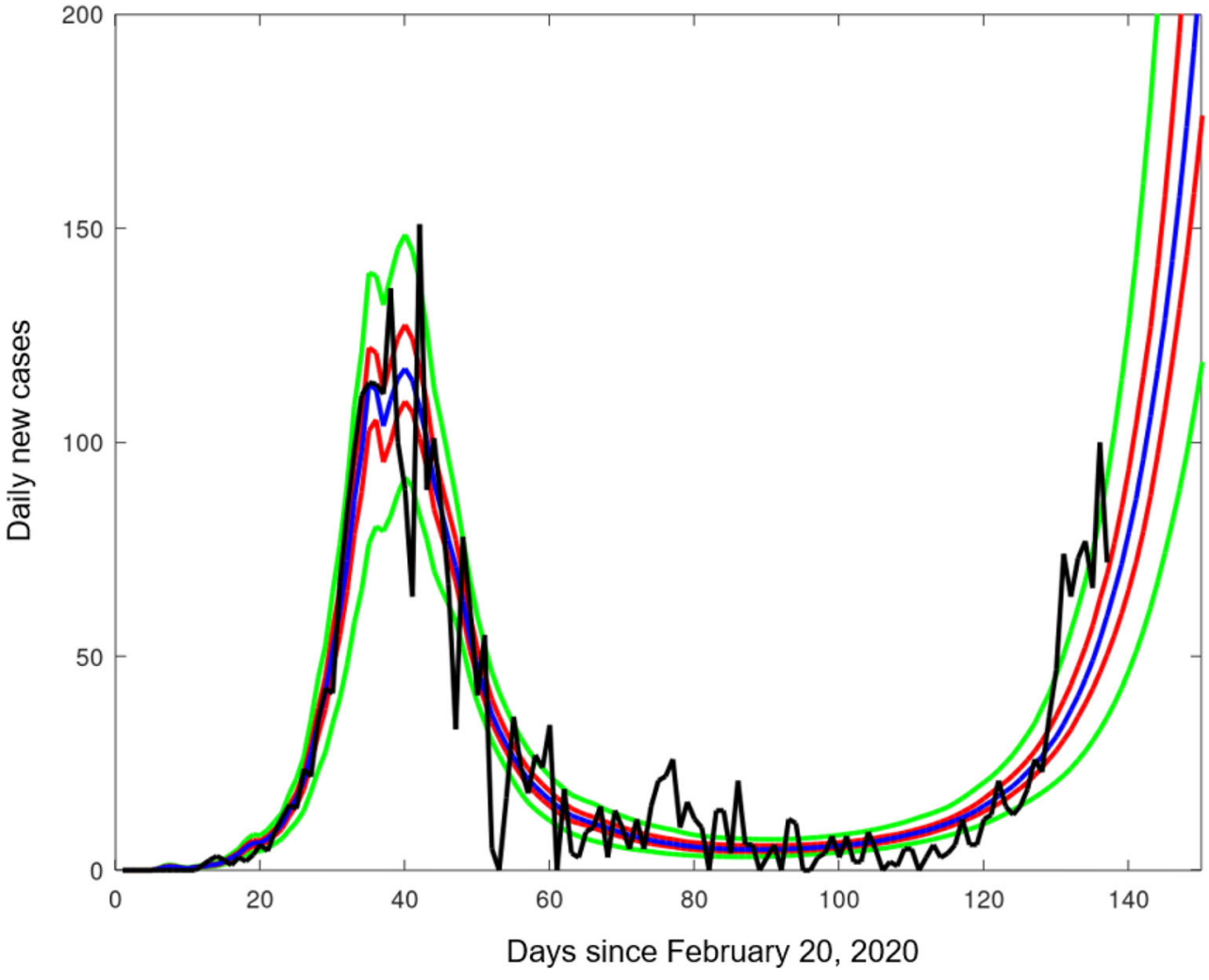

randomly from the posterior, are compared with the observations in Fig. 4. The fit is good, but we observe that the model does not adequately capture the steep rise in reported cases in the state of Victoria in late June - early July 2020. Percentiles for an equivalent ensemble from the SCM are shown in Fig. 5. The median predictions for the SCM and DCM agree closely.
Fig. 5 Daily new Australian cases of local origin from 20 February 2020. Observations in black; percentiles for a posterior ensemble from the SCM: median (blue), quartiles (red), 2.5 and 97.5 percentiles (green)

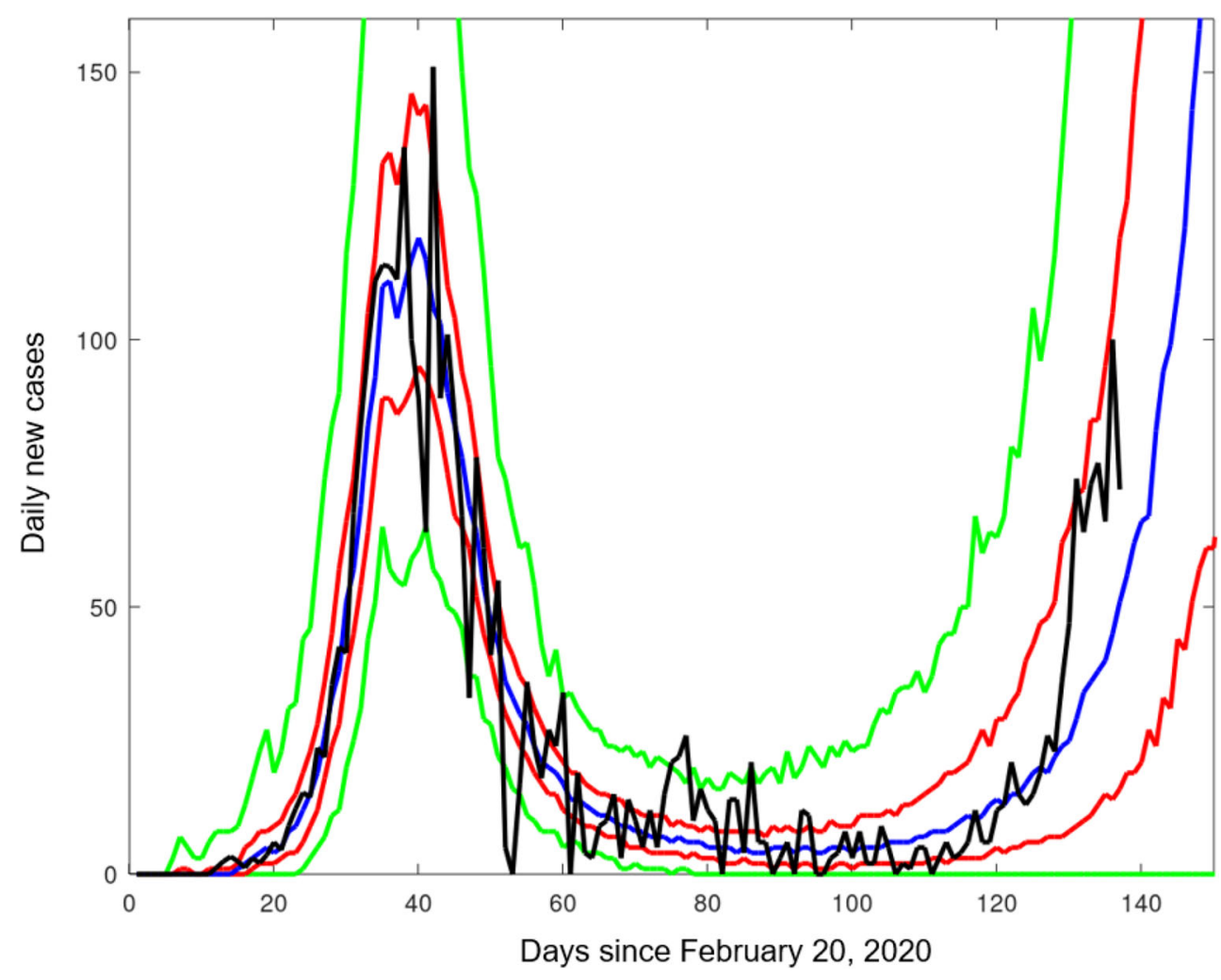


Fig. 6 Cumulative COVID-19 fatalities for Australia starting 20 February 2020. Observations in black; percentiles for a posterior ensemble from the SCM: median (blue), quartiles (red), 2.5 and 97.5 percentiles (green)

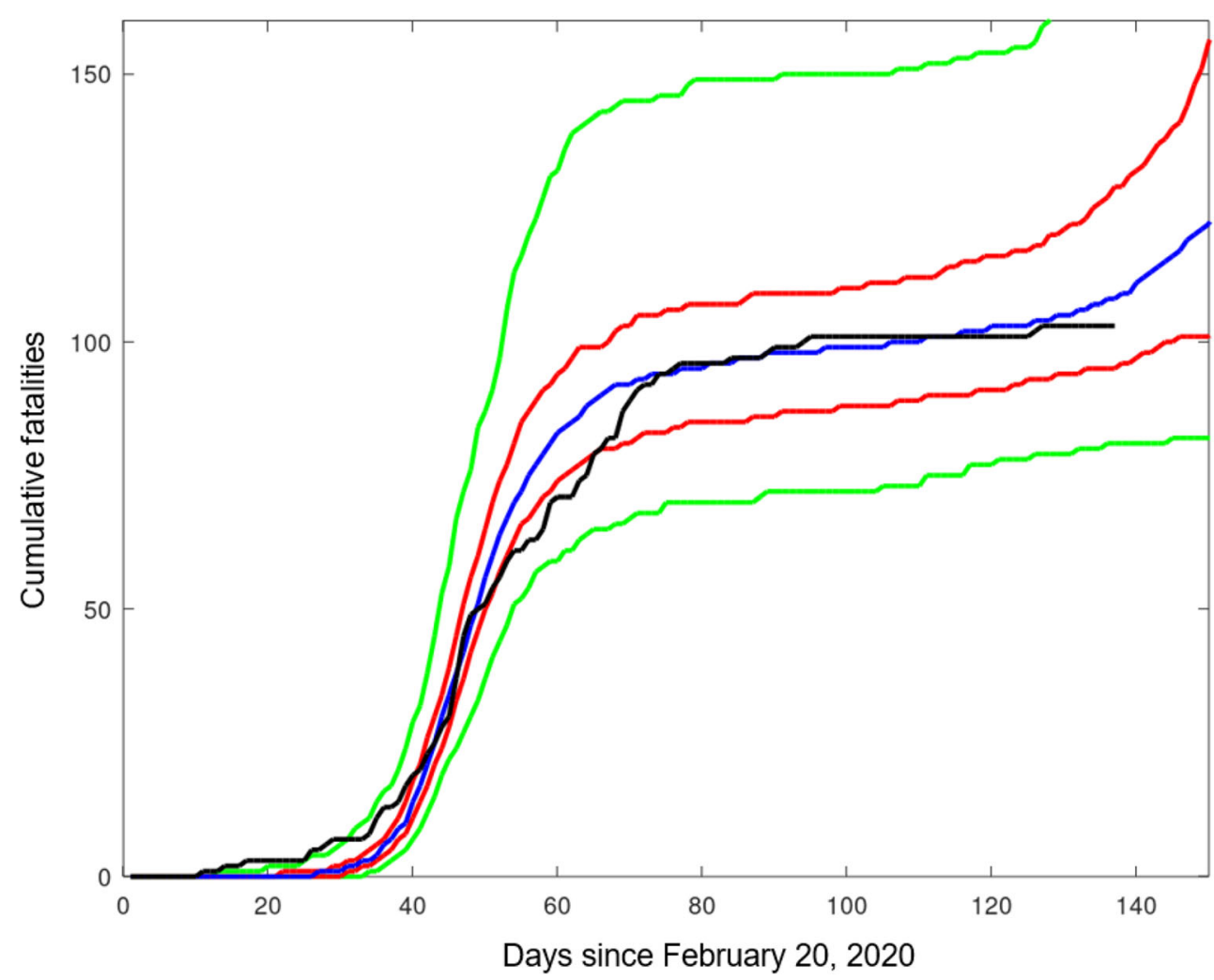

The SCM ensemble shows additional spread due to stochastic effects, and the observed steep increase in detected local cases in late June - early July 2020 does lie within the inter-quartile credibility interval for the stochastic model.
Fig. 7 Cumulative COVID-19 recoveries for Australia starting 20 February 2020. Observations in black; percentiles for a posterior ensemble from the SCM: median (blue), quartiles (red), 2.5 and 97.5 percentiles (green)

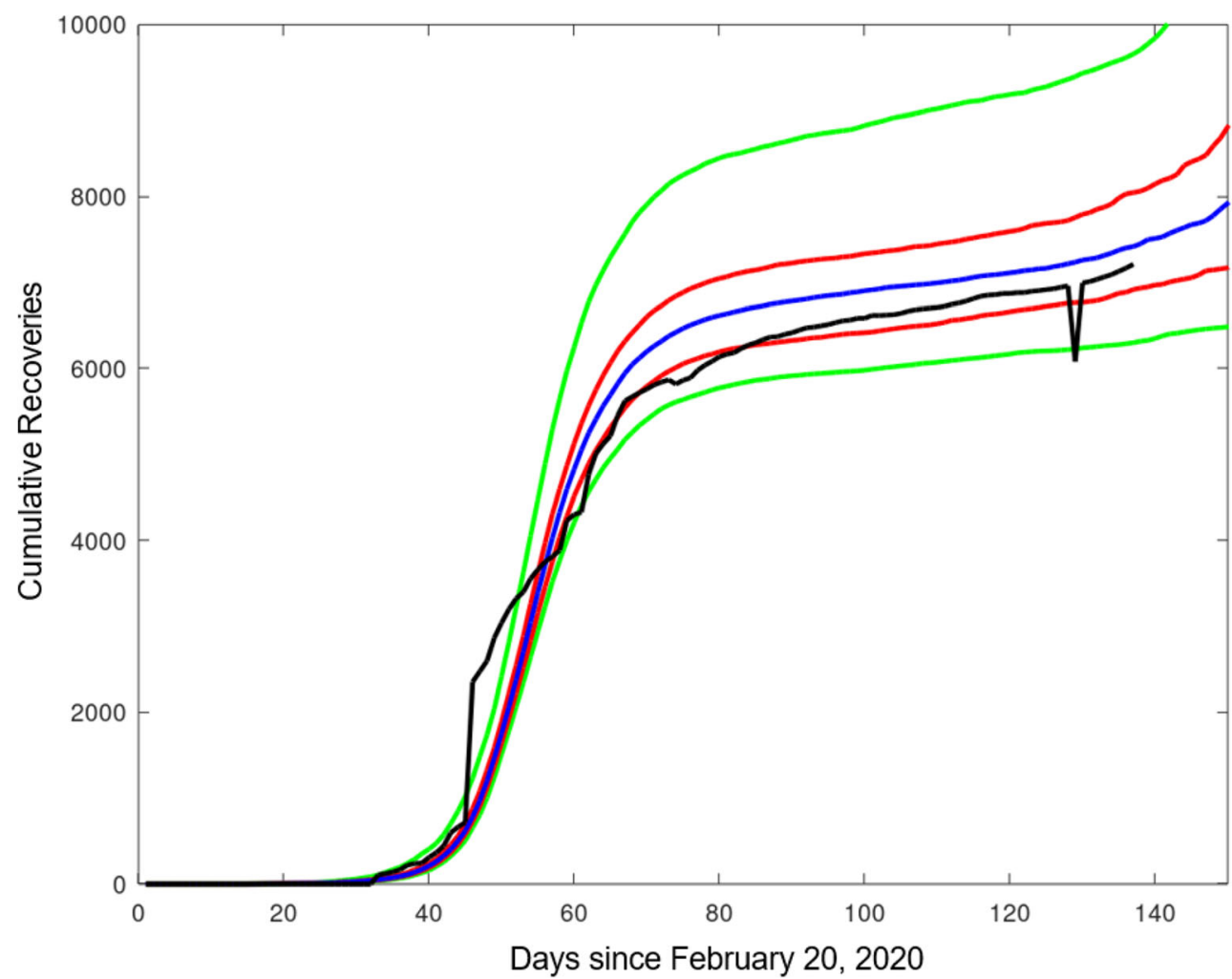


Fig. 8 a Marginal posterior pdfs for parameters subject to Bayesian inference. b Marginal posterior pdfs for parameters subject to Bayesian inference
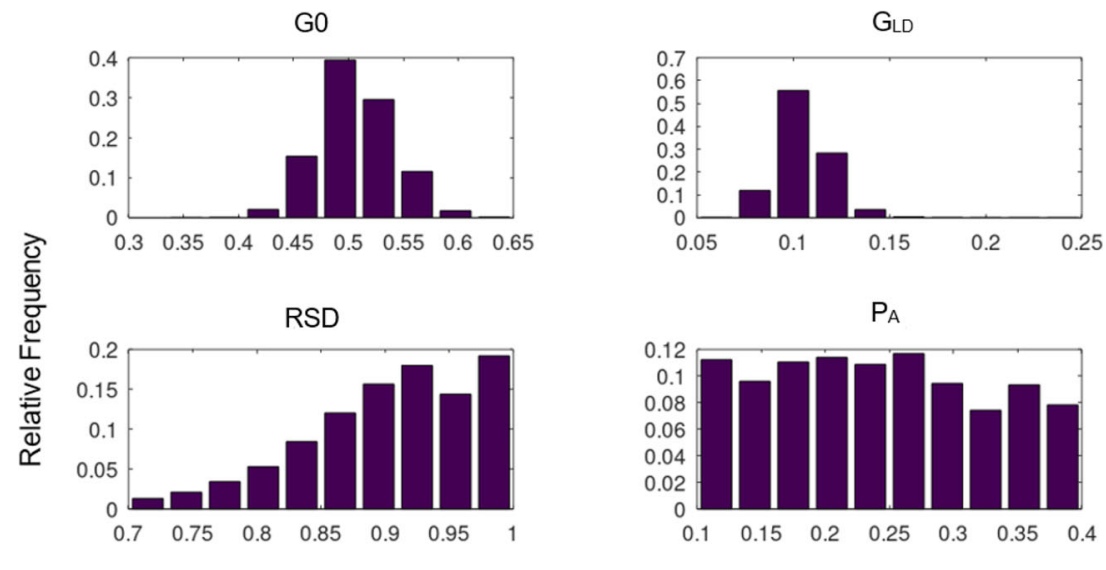

$\mathrm{F}_{\mathrm{A}}$

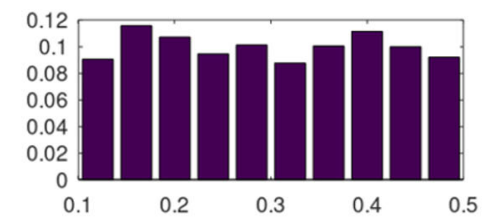

$\mathrm{P}_{\mathrm{A}}$

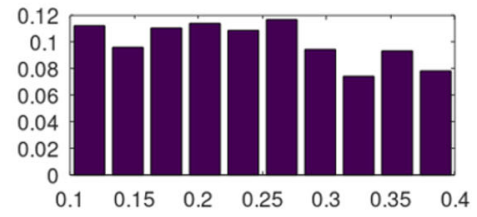

Pu

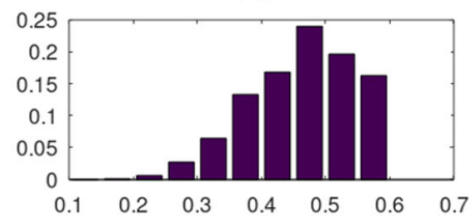

PDC

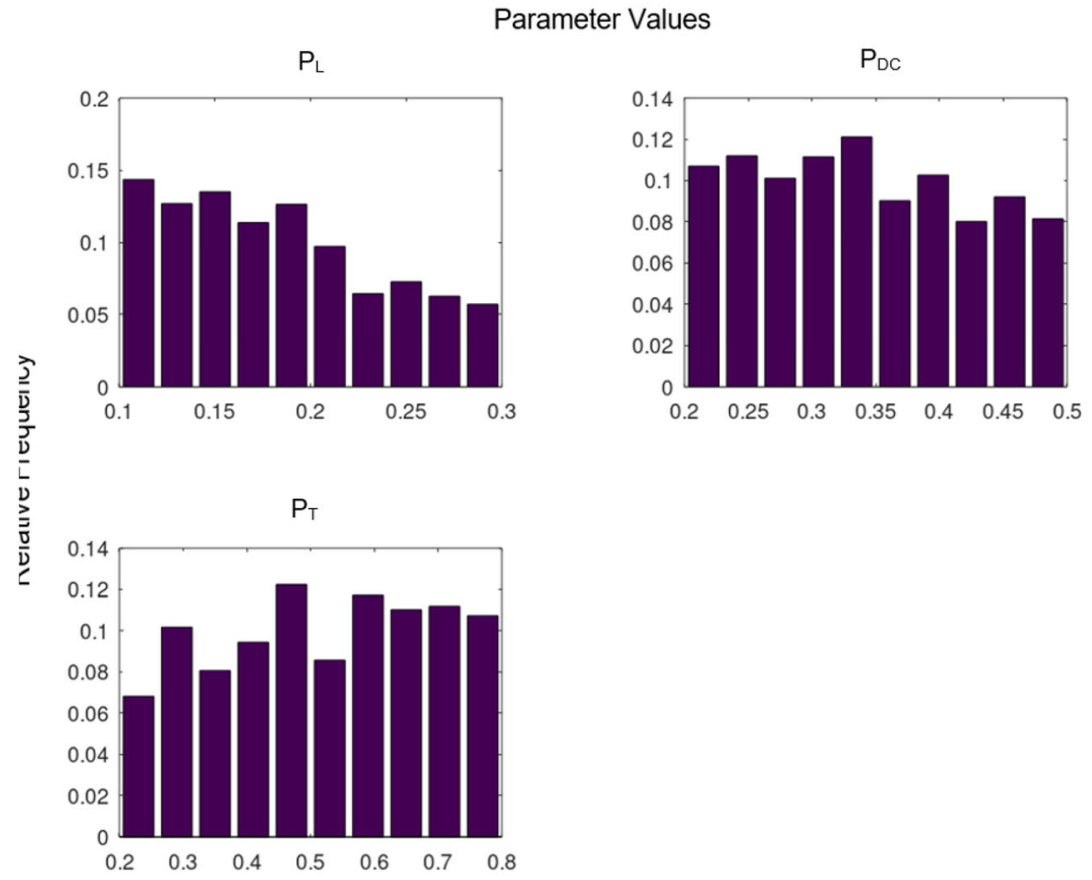

Parameter Values

Parameter Values

SCM posterior ensemble predictions of cumulative deaths are compared with observations in Fig. 6. The chosen parameter values for $T_{D}, P_{M}$ and $P_{D}$ (Table 2) provide a good approximation to the timing and magnitude of observed cumulative deaths through the 'first wave'. The second wave outbreak in Victoria that began in May 2020 started in a relatively younger demographic of workers and students, and only later spread into aged care homes beginning in July 2020 that resulted in over $90 \%$ of the Victoria second-wave fatalities.
The chosen values for parameters $T_{R}$ and $P_{R}$ (Table 2) leads to reasonable agreement in the timing of predicted and observed recoveries (Fig. 7), given some reporting anomalies in the observations. The median model prediction slightly over predicts recoveries, but given the good fit to daily cases, this may be because of incomplete official reporting of recoveries.

The marginal posterior pdfs for the parameters, calculated from the posterior weighted sample, are plotted as histograms 
Fig. 9 Posterior correlation structure among parameters subject to Bayesian inference

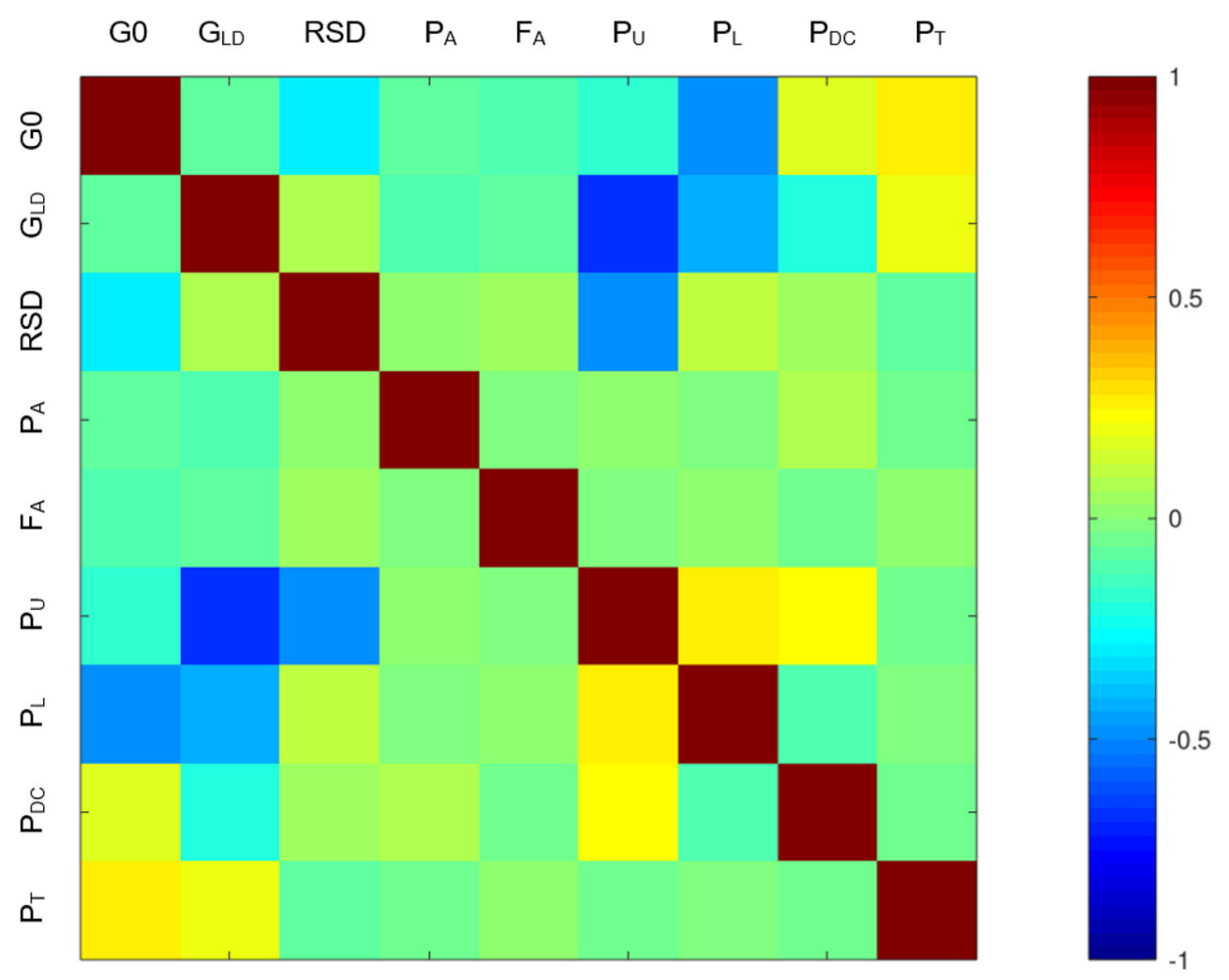

in Fig. 8. The parameters fall into three groups with respect to the information provided by the observations. The parameters G0 and $\mathrm{G}_{\mathrm{LD}}$ are highly informed, with posterior values restricted to a narrow range. The parameters $R S D, P_{U}$ and $P_{L}$ are moderately informed, with RSD biased to high values between 0.8 and $1, \mathrm{P}_{\mathrm{U}}$ to high values from 0.4 to 0.6 and $\mathrm{P}_{\mathrm{L}}$ biased towards low values from 0.1 to 0.2 . The remaining parameters seem to be effectively uninformed, with little difference between prior and posterior.

The posterior distribution carries additional information in the form of correlations among parameters (Fig. 9). A strong negative correlation between $\mathrm{G}_{\mathrm{LD}}$ and $\mathrm{P}_{\mathrm{U}}$ suggests the model is relying partly on contact tracing to bring about the steep decline in local cases in March-April 2020. High values of $\mathrm{P}_{\mathrm{U}}$ (high levels of untraceable cases) weaken contact tracing, and more effective social distancing (lower $\mathrm{G}_{\mathrm{LD}}$ ) is then required to match observations. There are also moderate negative correlations between RSD and $\mathrm{P}_{\mathrm{U}}$, and between $\mathrm{G} 0, \mathrm{G}_{\mathrm{LD}}$ and $\mathrm{P}_{\mathrm{L}}$, with similar explanations. A weaker positive correlation between $\mathrm{G} 0$ and $\mathrm{P}_{\mathrm{T}}$ suggests contact tracing reduces net transmissions prior to implementation of social distancing. The positive correlation between $\mathrm{P}_{\mathrm{U}}$ and $\mathrm{P}_{\mathrm{L}}$ may be an indirect result of their mutual strong negative correlations with transmission coefficients.

The DCM provides a relatively tight fit to observations despite some of the parameters being relatively poorly informed. This may be partly attributed to trade-offs among parameters, reflected in the correlation structure, although poorly informed and weakly correlated parameters such as $\mathrm{P}_{\mathrm{A}}$ and $\mathrm{F}_{\mathrm{A}}$ presumably have little influence on model predictions.

Our intent here was to provide decision-makers with a realistic picture of the uncertainty around the potential outcomes of alternative control strategies. We contend that scenario ensembles from the SCM, based on random samples from this posterior, provide a realistic picture of model uncertainty given prior knowledge and Australian observations to 5 July 2020.

Author contributions Conceptualization: R. Quentin Grafton, John Parslow, Tom Kompas, Kathryn Glass, Emily Banks; Investigation: John Parslow, R. Quentin Grafton, Tom Kompas, Kathryn Glass.; Validation: John Parslow, R. Quentin Grafton, Tom Kompas, Kathryn Glass; Writing - original draft: R. Quentin Grafton, John Parslow, Tom Kompas, Kathryn Glass, Emily Banks; Writing - review \& editing: R. Quentin Grafton, John Parslow, Tom Kompas, Kathryn Glass, Emily Banks.

Funding The authors received no direct funding for this research.

Availability of data and material (data transparency) Can be accessed at https://osf.io/2r9h6/

Code availability (software application or custom code) Can be accessed at https://osf.io/2r9h6/ 


\section{Declarations}

Conflicts of interest The authors have no conflicts of interest in relation to any part of the research including the modelling and reporting of the results.

Open Access This article is licensed under a Creative Commons Attribution 4.0 International License, which permits use, sharing, adaptation, distribution and reproduction in any medium or format, as long as you give appropriate credit to the original author(s) and the source, provide a link to the Creative Commons licence, and indicate if changes were made. The images or other third party material in this article are included in the article's Creative Commons licence, unless indicated otherwise in a credit line to the material. If material is not included in the article's Creative Commons licence and your intended use is not permitted by statutory regulation or exceeds the permitted use, you will need to obtain permission directly from the copyright holder. To view a copy of this licence, visit http://creativecommons.org/licenses/by/4.0/.

\section{References}

Australian Department of Health (2020a) Impact of COVID-19 in Australia - ensuring the health system can respond. Australian Department of Health: Impact of COVID-19. https://www.health. gov.au/resources/publications/impact-of-covid-19-in-australiaensuring-the-health-system-can-respond. Accessed 31 July 2020

Australian Department of Health (2020b) COVD-19 Current situation and case numbers. https://www.health.gov.au/news/health-alerts/ novel-coronavirus-2019-ncov-health-alert/coronavirus-covid-19current-situation-and-case-numbers. Accessed 10 December 2020

Blakely T, Thompson J, Carvalho N, Bablan L, Wilson N, Stevenson M (2020) Maximizing the probability that the 6-week lock-down in Victoria delivers a COVID-19 free Australia. Med J Aust. https:// www.mja.com.au/journal/2020/maximizing-probability-6-weeklock-down-victoria-delivers-covid-19-free-australia [preprint, 17 July 2020]
Chang SL, Harding N, Zachreson C, Cliff OM, Prokopenko M (2020) Modelling transmission and control of the COVID-19 pandemic in Australia. Nat Commun 11:5710. https://doi.org/10.1038/s41467020-19393-6

Grafton RQ, Parslow J, Kompas T, Glass K, Banks E (2020) What can we learn from the Victoria (Australia) versus Western Europe COVID-19 'Second Wave' Responses? SSRN. https://papers.ssrn. $\mathrm{com} / \mathrm{sol} /$ papers.cfm?abstract_id=3744720. Accessed 11 December 2020

Group of 8 Universities (2020) COVID-19 roadmap to recovery: a report to the nation. https://go8.edu.au/research/roadmap-to-recovery. Accessed 10 December 2020

Hunt G (2020) First confirmed case of novel coronavirus in Australia. https:/www.health.gov.au/ministers/the-hon-greg-hunt-mp/media/ first-confirmed-case-of-novel-coronavirus-in-australia. Accessed 31 July 2020

Kompas T, Grafton RQ, Che TN, Chu L, Camac J (2020) Health and economic costs of early, delayed and no suppression of COVID-19: the case of Australia. PLoS One 16(6):e0252400. https://doi.org/10. 1371/journal.pone.0252400

Legal and Social Issues Committee, Parliament of Victoria (2020) Inquiry into the Victorian Government's COVID-19 contact tracing system and testing regime. https://www.parliament.vic.gov.au/file_uploads/ LCLSIC_59-05_Vic_Gov_COVID-19_contact_tracing_testing wtnKCs70.pdf. Accessed 10 December 2020

Prime Minister and Cabinet (2020) Best practice regulation guidance note: value of statistical life. www.pmc.gov.au. Accessed on 10 May 2020

Saul A, Scott N, Crabb BS, Majumdar SS, Coghlan B, Hellard ME (2020) Victoria's response to a resurgence of COVID-19 has averted 9,000-37,000 cases in July 2020. Med J Aust. https://www.mja.com. $\mathrm{au} /$ journal/2020/victorias-response-resurgence-covid-19-hasaverted-9000-37000-cases-july-2020 [pre-print, 4 august 2020]

Victorian Department of Health and Social Services (2020) Coronavirus (COVID-19) roadmap for reopening. https://www.coronavirus.vic. gov.au/coronavirus-covid-19-restrictions-roadmaps. Accessed 10 December 2020

Publisher's note Springer Nature remains neutral with regard to jurisdictional claims in published maps and institutional affiliations. 